\title{
Short-term Functional Outcome in Psychotic Patients. Results of the Turku Early Psychosis Study (TEPS).
}

\author{
University of Turku \\ Tiina From \\ University of Turku \\ Tuula llonen \\ University of Turku \\ Sinikka Luutonen \\ University of Turku \\ Markus Heinimaa \\ University of Turku \\ Reetta-Liina Armio \\ University of Turku \\ Heikki Laurikainen \\ University of Turku \\ Maija Walta \\ University of Turku \\ Janina Paju \\ University of Turku \\ Anna Toivonen \\ University of Turku \\ Päivi Jalo \\ Turku University Hospital \\ Lauri Tuominen \\ Royal Ottawa Mental Health Centre \\ Jarmo Hietala \\ University of Turku
}

Raimo K. R. Salokangas ( $\square$ Raimo.K.R.Salokangas@utu.fi )

\section{Research Article}

Keywords: Functional Outcome, Psychotic Disorders, Clinical High Risk to Psychosis, Premorbid Adjustment, Disorganized Symptoms, Negative Symptoms

Posted Date: April 21st, 2021

DOI: https://doi.org/10.21203/rs.3.rs-423082/v1

License: (c) (i) This work is licensed under a Creative Commons Attribution 4.0 International License. Read Full License

Version of Record: A version of this preprint was published at BMC Psychiatry on December 1st, 2021. See the published version at https://doi.org/10.1186/s12888-021-03516-4. 


\section{Abstract}

Background: Functional recovery of patients with clinical and sub-clinical psychosis is associated with clinical, neuropsychological and developmental factors. Less is known how these factors predict functional outcome in same models. We investigated functional outcome and its predictors in patients with first-episode psychosis (FEP) or confirmed vs. non-confirmed clinical high risk to psychosis (CHR-P vs. CHR-N).

Methods: Altogether, 130 FEP, 60 CHR-P and 47 CHR-N patients were recruited and extensively examined at baseline (T0) and at 9 (T1) and 18 (T2) months after baseline. Global Assessment of Functioning (GAF) at T0, T1 and T2, and psychotic, depression, and anxiety symptoms at T1 and T2 were assessed. Functional outcome was predicted in multivariate repeated ANOVA.

Results: During follow-up, GAF improved significantly in FEP and CHR-P but not in CHR-N patients. In FEP, single marital status, low basic education, poor work situation, disorganised symptoms, perceptual deficits, and poor premorbid adjustment, in CHR-P, disorganised symptoms and poor premorbid adjustment and in CHR-N, low basic education, poor work situation and general symptoms predicted poor functional outcome. In FEP, psychotic symptoms at T1 and in CHR-P, psychotic and depression symptoms at T1 and anxiety symptoms at T2 associated with poor functioning.

Conclusions: In FEP and CHR-P patients, poor premorbid adjustment and disorganised symptomatology are common predictors for functional outcome, while poor education and work situation predict poor functional outcome in FEP and CHR-N patients. Interventions aimed to improve studying and ability to work are most important in improving functioning of patients with clinical or subclinical psychosis.

\section{Background}

Psychoses cause great human, medical, social and economic burden to the sick individuals, their families and to the whole society $[1,2]$ and are associated with reduced life expectancy of 15-20 years [3] Therefore, clarification of the factors affecting outcome in patients with psychoses has been and still is of a great importance.

Clinical outcome of schizophrenia is still rather poor [4,5] need for care high 6 and ability to work very low [7] Compared to other psychotic disorders, schizophrenia consistently shows poorer courses and outcomes [8]. Poor premorbid personality and psychosocial development, slow illness development, young age at the onset of illness, male gender, single marital status, lack of interpersonal network, abuse of alcohol and drugs are associated with poor outcome, and from clinical characteristics, severe negative symptoms, neurocognitive deficits and slow or partial recovery after the first illness episode have been associated with poor outcome [9-22].

In terms of neurocognitive deficits, most pronounced impairments have been found in processing speed and episodic memory [23-28]. However, during a long-term follow-up of patients with schizophrenia, baseline neurocognitive impairments did not correlate with clinical outcome [29]. In addition, childhood adversities have been associated with psychotic disorders [30-33]. Less is known of their role in prediction of functional outcome of patients with psychosis.

The studies on patients with high risk to psychosis (CHR-P) have mainly focused on transition to psychosis and its prevention [34-36]. Since these earlier studies, the rate of onset of psychoses among CHR-P patients is declined, being today at the level of about $20 \%$ in two-year follow-ups [37, 38]. According to a meta-analysis, both psychological and pharmacological interventions seem to reduce or delay conversion to psychosis, but hardly improve functional outcome in relation to the control conditions [39].

The CHR-P patients are characterised with many clinical disorders including impairments in work or educational functioning, social functioning and quality of life [40]. In addition to brief limited psychotic symptoms, e.g. positive symptoms, bizarre thinking, schizotypal personality disorder/features, depression, disorganization and neurocognitive deficits and poor psychosocial adjustment have been risk factors for transition to psychosis in patients with CHR-P [41-47].

In various studies, processing speed, deficits in motor speed, verbal memory, verbal learning, verbal fluency and executive function have been associated with onset of psychosis and poor functioning [47-54]. According to a systematic review, negative and disorganised symptoms and cognitive deficits pre-date frank psychotic symptoms and are risk factors for poor functioning [55]. Additionally, patients with CHR-P often report high levels of childhood adversities [56,57]. In follow-up studies, childhood adversities have predicted depression, poor social functioning and suicidal thinking [58-59].

Premorbid psychosocial development and its role as a predictor of outcome has received less attention. In an outcome study of CHR-P patients, premorbid psychosocial adjustment, baseline negative symptoms and poor working/schooling situation predicted poor follow-up functional outcome [60]. Also in other studies, negative symptoms, impairments in role and social functioning have predicted poor functional outcome at follow-up [52, 53, 61].

The literature above indicates that a great number of individual factors associate with functional outcome in patients with clinical or sub-clinical psychotic symptoms. It is probable that the effects of these factors overlap each other. Less is known, which of them has an independent effect on patients' functional outcome.

Aims of the Study 
In this outcome study, which is a part of the Turku Early Psychosis Study (TEPS), we aimed to investigate 1) the short-term (up to about 18 months) functional outcome of the patients with first-episode psychosis (FEP), confirmed (CHR-P) or non-confirmed clinical high risk to psychosis (CHR-N) and 2) the factors predicting functional outcome in these three patient groups.

\section{Material And Methods}

In Supplementary Material, we have described the methods of the TEPS project in detail. Here we concentrate on the methods of the TEPS functional outcome study comprising patients with FEP, CHR-P and CHR-N. The TEPS study programme was carried out in accordance with the latest version of the Declaration of Helsinki. The study design and protocols were approved by the ethical committee of the Turku University Hospital. Informed written consent from participants was obtained after the procedure had been fully explained to them.

Participants

The study patients of age 18 to 50 were recruited from mental hospitals $(N=183)$, psychiatric outpatient centres $(n=101)$ and primary care $(n=19)$ of the Turku University Hospital District in Finland between October 2011 and December 2017.

When an eligible patient attended for the first time the psychiatric/primary care services, the personnel filled in a screen, taking a stand whether the patient was possibly psychotic or at high risk to psychosis. The TEPS study group assessed the completed screens and invited the patients, possibly fulfilling the inclusion criteria, to the study examinations. FEP was defined by the DSM-IV criteria and included schizophrenia, delusional and bipolar psychoses, acute transient and other psychoses. CHR-P was defined by the ultra-high-risk criteria: Attenuated Psychotic Symptoms (APS), Brief Limited Psychotic Symptoms, and Genetic risk and reduction of function assessed by the 3.0/5.0 version of the Structured Interview for Prodromal Syndromes (SIPS/SOPS) including Global Assessment of Functioning (GAF) $[62,63]$. The patients who, according to the health-care personnel, were at high risk to psychosis, but who in the diagnostic examination did not fulfil the SIPS/SOPS criteria, were patients with non-confirmed high risk to psychosis (CHR-N). Exclusion criteria for study patients were previous psychotic disorder and IQ < 70 The final TEPS sample comprises $130 \mathrm{FEP}, 60 \mathrm{CHR}-\mathrm{P}$, and $47 \mathrm{CHR}-\mathrm{N}$.

\section{Baseline examinations}

At the baseline, the study patients went through extensive examinations (Supplementary Material). For this outcome study, in addition to socioeconomic background, patients' premorbid adjustment (PAS) [64], Axis I diagnosis (SCID-l; DSM-IV) [65] and clinical high risk to psychosis (SIPS/SOPS, including GAF) $[62,63]$ were obtained in interview. Additionally, patients fulfilled questionnaires on childhood adverse and trauma experiences (TADS) [66, 67] and social support or confidants (PSS-R) [68].

PAS evaluates difficulties in individuals' premorbid adjustment (rated from 0 to 6 ) during four time domains: childhood (up to 11), early (12-15) and late adolescence (16-18) and in adulthood (19+). Because not all participants had reached adulthood, only the childhood, early and late adolescence PAS domain scores were used in analyses.

In SIPS/SOPS, 5 positive, 6 negative, 4 disorganised and 4 general symptoms, schizotypal personality disorder and functioning (GAF) are assessed [62, 63]. In the present study, we used sums of positive, negative, disorganised and general symptoms as clinical predictors.

The TADS, validated in a general population sample [67] produces five core domains: emotional abuse (EmoAb), physical abuse (PhyAb), sexual abuse (SexAb), emotional neglect (EmoNeg) and physical neglect (PhyNeg).

The social supports questionnaire (PSS-R) [68] comprises lists of 12 questions on support received $(0=$ never, $1=$ hardly ever, $2=$ sometimes, $3=$ most of time and 4 = all the time) from family and friends. Sum score (range $0-48$ ) were used as an indicator of confidant support, shortly confidants.

Neuropsychological tests were not performed before the psychotic patients were recovered from their manifest psychosis; usually 3 to 4 weeks after admission to a hospital ward. The domains and tests included were as follows: Estimate of premorbid cognitive functioning (Vocabulary, WAIS-III) [69], letter (S) and category (animals) fluency [70,71] attention/vigilance (Trail Making A/B) [72] speed of processing (Digit Symbol, WAIS-III), verbal and visual working memory (Letter-Number Span, WAIS-III and Spatial Span WMS-R) [73] verbal learning (Hopkins Verbal Learning Test-Revised, HVLT) [74] visual learning (Brief Visuospatial Memory test-Revised, BVMT-R) [75] reasoning and problem solving (Neuropsychological Assessment Battery, Mazes) [76] perceiving and forming concepts in a complex problem solving situation (Rorschach Comprehensive System, RCS) [77, 78] executive function (Wisconsin Card Sorting Test, WCST) [79] and social cognition (Mayer-Salovey-Caruso Emotional Intelligence Test, MSCEIT, Managing Emotions, D and H) [80].

Follow-up examinations

When nine (T1) and 18 (T2) months were elapsed from the basic examination, patients were invited for follow-up examinations. For this outcome study, GAF, as well as occurrence of psychotic (yes/no), depression (yes/no) and anxiety (yes/no) symptoms at the follow-up points (T1 and T2) were recorded and transition to psychosis was detected [43]. Due to drop-outs, information regarding both functioning (GAF) and psychiatric symptoms at follow-ups were supplemented by scrutinising patients' medical case notes and by telephone interview of patients and/their relatives and/or their doctors (RKRS) as described in detail in Supplementary Material. 
First, distributions of background factors were cross-tabulated and means (SD) of GAF, SIPS, TADS, confidant support, PAS scores and neuropsychological test scores were calculated by diagnostic groups and tested by Chi test and ANOVA. Repeated measures ANOVA over the whole study period (GAFT0, GAFT1 and GAFT2) were calculated for diagnostic group and each baseline characteristic, SIPS and TADS domain, three PAS domain scores and for each neuropsychological test.

In multivariate repeated measures ANOVAs, functioning over the study period (GAFT0, GAFT1 and GAFT2) was explained by blocks of independent variables: 1) diagnosis and background factors, 2) SIPS domain scores (positive, negative, disorganised and general) and confidant support, 3) neuropsychological test scores 4) TADS domains and 5) PAS domain scores. At each stage, non-significant ( $p>0.1)$ factors were omitted, and the rest of variables were included into modelling with the next block of variables. In the final model, only the factors with significant association ( $p<0.05)$ with functioning were included into equation. Thereafter, psychotic, depression and anxiety symptoms at T1 and T2 were entered into the final model for analysing how follow-up symptoms change the model's explanatory power. Analyses were performed for all study subjects and for FEP, CHR-P and CHR-N patients separately. Data were analysed using Statistical Programme for the Social Sciences (SPSS) v24.0, and p-values $<0.05$ were considered significant.

\section{Results}

Baseline characteristics

In terms of sociodemographic factors, social support included, there were no differences between FEP, CHR-P and CHR-N patients. In FEP patients, one third had an affective and two thirds non-affective psychosis. Majority of the CHR-P and CHR-N patients suffered from depressive and anxiety disorders; difference was non-significant ( $p=0.369$ ) (Table 1). Psychotic symptoms, which were used as diagnostic criteria for FEP, CHR-P and CHR-N, increased linearly from CHR-N to CHR-P $(p<0.001)$ and from CHR-P to FEP $(p<0.001)$. In disorganised symptoms, differences between FEP and CHR-N $(p=0.001)$ and CHR-P and CHR-N ( $p=0.046)$ were also significant. In negative and generalised symptoms, in TADS domains and PAS domain scores, there were no significant differences between diagnostic groups (Table 1)

In general, FEP patients had more difficulties in keeping attention, speed of processing, working memory, verbal and visual learning, reasoning and problem solving than CHR-P or CHR-N patients; differences between CHR-P and CHR-N patients were non-significant (Table 2). In WCST and Ro, FEP patients managed poorer than CHR-N patients and in Ro CHR-P patients poorer than CHR-N patients (Table 2).

Functioning at baseline and follow-ups

At the baseline, functioning of patients with FEP was poorer than that of patients with CHR-P $(p=0.004)$ and $C H R-N(p<0.001)$. The difference between CHR-P and CHR-N patients was not significant $(p=0.072)$. During the follow-up, functioning of patients with FEP and CHR-P improved significantly, but not in CHR-N patients (Table 3). At T1 and T2, there were no significant differences in functioning between diagnostic groups (Table 3).

Univariate prediction of functioning

In repeated measures ANOVA for GAFT0, GAFT1 and GAFT2, diagnostic groups (FEP/CHR-P/CHR-N) $(p=0.064)$ and SCID diagnosis groups $(p=0.140)$ did not associate significantly with functional outcome. From the baseline characteristics, female gender $(p=0.001)$, non-single marital status $(p=$ $0.005)$, confidant support $(p=0.005)$, good basic $(p<0.001)$ and professional education $(p<0.001)$ and good work situation $(p<0.001)$ predicted good functioning (Table 4). In FEP patients, these associations were similar as in the entire patient sample. In CHR-P patients, only gender and work situation and in CHR-N patients, basic and professional education and work situation associated with follow-up functioning (Supplementary Table 1).

All SIPS symptoms, PAS domains and PhyAb from TADS associated significantly with the functioning (Supplementary Table 2). In FEP patients, all SIPS symptoms, and all PAS domains, in CHR-P patients, SIPS negative and disorganised symptoms, PhyAb and all PAS domains and in CHR-N patients, all SIPS symptoms, EmoAb and PhyAb associated significantly with the follow-up functioning. In FEP and CHR-P but not in CHR-N, both childhood, early and late adolescence PAS scores associated with follow-up functioning (Supplementary Table 2).

From neuropsychological tests, WAIS IQ (vocabulary), word fluency, divided attention (TMTB), speed of processing, verbal and visual working memory, verbal and visual learning and problem solving associated with functioning. From WCST, number of errors, conceptual responses and from RCS test perceptual problems (PTI, X-\%, XA\%, WDA\%) associated with functioning. In FEP, vocabulary, word fluency, visual working memory, visual learning, and perceptual disturbances, in CHR-P, sustained attention (TMTA), verbal working memory and WCST scores and in CHR-N, vocabulary and attention (TMTA) associated with functioning (Supplementary Table 3).

Multivariate prediction of follow-up functioning

In multivariate repeated ANOVAs for GAFT0, GAFT1 and GAFT2, predictors were added into models in order as described in Methods. In the entire patient sample, good basic education and work situation, lack of disorganisation symptoms and perceptual deficits and good premorbid late adolescence adjustment predicted good functioning. Together these factors explained $38.8 \%$ of the variance of functioning (Table 4 ). 
In sensitivity analyses for FEP, marital status $(p=0.001)$, basic education $(p=0.012)$, work situation $(p=0.002)$, SIPS disorganised symptoms $(p<$ $0.001)$, perceptual problems (XA\%; $p=0.028)$ and late adolescence PAS scores $(p=0.003)$ associated significantly with functioning (Supplementary Table 4a). In CHR-P patients, only baseline SIPS disorganised symptoms ( $p=0.008)$ and childhood PAS ( $p=0.004)($ Supplementary Table $4 b)$, and in CHR-N patients, basic education $(p=0.001)$, work situation $(p=0.009)$ and SIPS general symptoms $(p=0.006)$ associated with functioning (Supplementary Table 4c). The proportion of variance explained was for patients with FEP $55.6 \%$, CHR-P $24.2 \%$ and for CHR-N patients $72.5 \%$.

In final stage, psychotic, depressive and anxiety symptoms occurring at T1 and T2 were included into the outcome models. In the entire patient sample, T1 psychotic symptoms $(p<0.001)$, T2 depression $(p=0.001)$ and T2 anxiety symptoms $(p=0.006)$ entered into the equation and the proportion of variance explained increased from 38.8-63.3\%. In FEP patients, only T1 psychotic symptoms ( $<<0.001)$, in CHR-P patients T1 psychotic symptoms ( $p$ $=0.023)$, T1 depression $(p=0.002)$ and T2 anxiety symptoms $(p<0.001)$ and in CHR-N patients only T2 depression ( $p=0.046)$ symptoms entered into equation. The proportion of variance of the functioning explained, increased in FEP (from 55.6-73.8\%) and in CHR-P (from 24.2-90.0\%) but not in CHR$\mathrm{N}$ (from 72.5-68.5\%) patients. Transitions to psychosis (CHR-P: 13/60 [21.7\%]; CHR-N: 6/47 [12.8\%]) did not associate with functional outcome in either CHR groups.

\section{Discussion}

At the time of attendance to treatment, patients with FEP, CHR-P or CHR-N did not differ in their sociodemographic background, childhood adverse experiences and premorbid adjustment. In terms of premorbid functioning, CHR-P subjects did not differ from patients with first-episode psychosis or multi-episode schizophrenia [49].

At the baseline, functioning of patients with FEP was poorer than in CHR-P and CHR-N patients, but during the follow-up, this difference became equalised; functioning in FEP and CHR-P patients improved but not in CHR-N patients. In FEP patients, resolving of psychotic symptoms associating with reduced functioning at acute phase (Supplementary Table 2) possibly explained their good functional recovery. In CHR-P patients, recovery of functioning was slower and possibly correlated with improving in negative and disorganised symptoms (Supplementary Table 2). The interventions possibly focused on reduction of positive psychotic symptoms could not considerably improve functioning in the CHR-N patients.

At the eighteen months follow-up, $43.4 \%$ of FEP patients were functioning well, $29.5 \%$ moderately and $27.1 \%$ poorly. The proportion of patients with a good functioning was a little higher than in previous studies [81, 82]. It was remarkable that sociodemographic background, SIPS symptoms, neurocognitive deficits and premorbid adjustment associated extensively with functioning. However, in multivariate modelling, only basic education (high), work situation (good), disorganised symptoms (few), perceptual disturbances (few) and late adolescence premorbid adjustment (good) predicted significantly good functional outcome. However, constructions of predictive factors for functional outcome varied considerably between FEP, CHR-P and CHR-N patients.

In patients with FEP, marital status (single), poor basic education and poor work situation associated strongly with poor functional outcome. Marital status, education and work situation, central components of the social competence $[83,84]$ represent an endpoint of psychosocial development at the beginning of the first attendance to treatment. Interestingly, these three sociodemographic factors were still powerful predictors, although the effect of adolescence development [64] had been taken into account. Possibly, since adolescence occurring psychiatric symptomatology and neuropsychological deficits with difficulties in schooling, deviate both socio-sexual and work performance development to the low competence trajectory with further worsening after onset of psychosis. In chronic schizophrenia, extremely low competence was seen in single men whose quality of life was exceptionally low [85].

In patients with CHR-P and CHR-N, the role of education and work situation varied, being significant predictor in the latter and non-significant in the former. In our previous studies on CHR-P patients $[60,86]$ work situation and education predicted short-term follow-up functioning. In the present study, low number of CHR-P patients may explain the difference; in a combined sample both education and work situation were significant predictors (analyses available by request) indicating that they both are important predictors for functioning also in patients with sub-clinical psychotic symptoms.

From baseline symptoms, only SIPS disorganised symptoms had an independent predictive power on functional outcome both in FEP and CHR-P patients. The effect of negative symptoms on functioning, found in several studies on schizophrenia $[15,17,18,20,22]$ and in bivariate analyses of the present study, was replaced by the effects of work situation and disorganised symptoms. Positive symptoms correlated with baseline functioning, but in modelling, they did not significantly predict follow-up functioning. In a follow-up study of FEP patients, remission of negative symptoms was found to be critical in the prediction of future functioning [81] In line with earlier studies [20,22,60,87] among patients with clinical psychosis, major psychotic symptoms, delusions and hallucinations, their prevention hardly has a great effect on their functional outcome. In CHR-P patients, the role of positive symptoms is similar. Like in our previous studies $[60,86]$ in CHR-P patients, positive symptoms and transition to psychosis did not associate with functional outcome. Positive psychotic symptoms (like delusions and hallucinations) are specific predictors for new or incident psychotic disorders88-90 but they hardly play any role in predicting functional outcome in patients with CHR-P.

In bivariate analyses, various neurocognitive deficit indicators associated with functional outcome, but in multivariate modelling, only perceptual disturbances, assessed by the Rorschach Exner (RCS) test, had, specifically in FEP patients, an independent association with poor functional outcome. This kind of disturbances in visual form perceptions differ from sense disturbances, like hallucinations. Interestingly, deficits in visual learning (BVMT-R) associated also with poor functional outcome, but in modelling lost their predictive power when premorbid adjustment entered into the model. Anyway, 
perceptual disturbances, possibly caused by incoherent structure and function of CNS neuronal network, seem to play an important role in functional outcome among psychotic patients. In CHR-P and CHR-N patients, neurocognitive deficits played minor role in prediction of functional outcome. Thus, it seems that although, neurocognitive deficits are common in patients with FEP [23-28] and CHR-P [47-54] and correlate with actual functioning, their value in predicting function outcome is not great.

In accordance with earlier studies [14-22, 60] premorbid adjustment, assessed by the PAS scale64, associated strongly with functional outcome in the patients with FEP and CHR-P. In both patient groups, the late adolescence PAS had the strongest association with follow-up functioning. It is generally known that first signs of schizophrenia often occur in adolescence. While PAS assessment represents a global assessment of individuals' early psychosocial development, it also includes effects of genetic and environmental factors, like childhood adversities.

It was remarkable that although childhood adversities associate with onset of psychotic and sub-psychotic disorders, like CHR [30-33, 56, 57] and with transition to psychosis in patients with $\mathrm{CHR}, 91$ in multivariate modelling of the present study, they did not predict follow-up functioning.

Like in other studies on CHR-P [45,92] affective disorders, both depression and anxiety, were very common at the time of help seeking. During follow-up, transition to psychosis did not associate with functioning, and the association of positive psychotic symptoms was slight, while depressive and anxiety symptoms associated strongly with poorer functioning and increased the model's predictive power greatly. These findings indicate that affective, not positive psychotic symptomatology, is the major psychiatric symptomatology worsening functional outcome in CHR-P patients. Also, in other CHR-P studies, non-psychotic comorbidity has been associated with poor functional outcome [93, 94].

Comparison of short-term functional outcome between FEP and CHR-P patients suggests that they may represent qualitatively different groups of helpseekers. Individuals with FEP form a heterogenic group of psychotic patients among whom, together with previous psychosocial and educational development, disorganised symptoms are decisive clinical factors predicting functional outcome. CHR-P help-seekers represent individuals suffering from long-term affective disorders with mostly temporary, distress increasing psychotic/-like symptoms. In both groups of patients, resolving of positive symptoms correlates with functional improving, while continuation of affective (depression and anxiety) symptoms seem to prevent further improving of functioning. In patients with CHR-N, sub-clinical positive symptoms are mild and functional recovery minor. In all three patient groups, ability to work at the time of the first attendance to treatment is considerably reduced and greatly predict their further functioning.

\section{Conclusions And Implications}

During the follow-up, functional outcome of patients with FEP improved considerably being at the end of the follow-up at the same level as in patients with CHR-N, whose functioning did not improve significantly. More than $90 \%$ of patients with FEP received antipsychotic medication, which probably improved the lower functioning of FEP patients related to positive psychotic symptoms.

In addition to poor premorbid adjustment and disorganised symptomatology, poor education and work situation associated with poor functional outcome in patients with clinical or subclinical psychotic symptoms. Thus, for improving further functioning of psychotic and non-psychotic severely disturbed patients, psychosocial intervention aiming to improve studying and working ability are needed [95]. It has been found that supported education and employment can considerably improve school participation and ability to work in FEP patients [96] and that individual placement and support can improve ability to work and school, leading to competitive employment when compared with traditional vocational rehabilitation [97] Neurocognitive remediation combined with supported employment may further improve severely mentally ill patients' working ability [98-100]. The interventions aimed to treat depression-anxiety syndrome may improve functional outcome particularly in patients with CHR-P.

\section{Declarations}

\section{Ethics approval and consent to participate}

The TEPS study programme was carried out in accordance with the latest version of the Declaration of Helsinki. The study design and protocols were approved by the ethical committee of the Turku University Hospital. Informed written consent from participants was obtained after the procedure had been fully explained to them.

\section{Consent for publication}

Not applicable

\section{Availability of data and materials}

The TEPS data set is not available for ethical reasons. The study information to the participants and the informed consent they have fulfilled includes an expression that the data collected will be used only for this particular study, not for other purposes.

\section{Competing interests}

The authors declare that they have no competing interests.

Funding 
The TEPS has been funded by the EVO Funding of Turku City Health Care and Turku University Hospital (grant nos. TEPS600083, P13196, P3860, P3848) and by the Academy of Finland (grant nos. 278155 and 278171).

\section{Authors' contributions}

R.K.R.S and J.H. Study planning and leader, analysing, writing

T.F. Data managing and quality controlling, participating in coordination of examinations, participating in analyses and writing

T.I. Neuropsychological testing and participating in writing

S.L. and M.H. Participating in study planning, assessment of results and writing

R-L.A. and H.L. Neuroimaging and assessment of results, participating in writing

M.W. Participating in assessment of results, commenting manuscript

J.P. and A.T. Data collecting (interviews), Neuropsychological testing

P.J. Coordination on examinations, data collecting (interviews), quality control.

L.T. Participating in assessment of results and in writing

All authors approved the final manuscript as submitted.

\section{Acknowledgements}

The whole TEPS group is mentioned in Supplementary material.

\section{References}

1. WHO The Global Burden of Disease: Update 2008. http://www.who.int/topics/global_burden_of_disease/en/ Assessed March 22, 2021.

2. Gustavsson A, Svensson M, Jacobi F, et al. CDBE2010 Study Group. Cost of disorders of the brain in Europe 2010. Eur Neuropsychopharmacol. 2011;21(10):718-779. doi: 10.1016/j.euroneuro.2011.08.008.

3. Saha S, Chant D, McGrath J. A systematic review of mortality in schizophrenia: is the differential mortality gap worsening over time? Arch Gen Psychiatry. 2007;64(10):1123-1131. doi: 10.1001/archpsyc.64.10.1123. PMID: 17909124.

4. Kelly C, McCreadie RG, MacEwan T, Carey S. Nithsdale schizophrenia surveys. 17. Fifteen year review. Br J Psychiatry. 1998;172:513-517. doi: 10.1192/bjp.172.6.513. PMID: 9828992.

5. Jääskeläinen E, Juola P, Hirvonen N et al. A systematic review and meta-analysis of recovery in schizophrenia. Schizophr Bull. 2013;39(6):12961306. doi: 10.1093/schbul/sbs130. Epub 2012 Nov 20. PMID: 23172003; PMCID: PMC3796077.

6. Brown S, Birtwistle J, Roe L, Thompson C. The unhealthy lifestyle of people with schizophrenia. Psychol Med. 1999;29(3):697-701. doi: 10.1017/s0033291798008186. PMID: 10405091.

7. Honkonen T, Stengård E, Virtanen M, Salokangas RK. Employment predictors for discharged schizophrenia patients. Soc Psychiatry Psychiatr Epidemiol. 2007;42(5):372-380. doi: 10.1007/s00127-007-0180-5. Epub 2007 Mar 19. PMID: 17492406.

8. Jobe TH, Harrow M. Long-term outcome of patients with schizophrenia: a review. Can J Psychiatry. 2005;50(14):892-900. doi: 10.1177/070674370505001403. PMID: 16494258.

9. Vaillant GE. The prediction of recovery in schizophrenia. J Nerv Ment Dis. 1962;135:534-543. doi: 10.1097/00005053-196212000-00006. PMID: 13995749.

10. Astrup C, Noreik K. Functional psychoses. Diagnostic and prognostic models. Springfield: Charles C Thomas; 1966.176 p.

11. Noreik K, Astrup C, Dalgard OS, Holmboe R. A prolonged follow-up of acute schizophrenic and schizophreniform psychoses. Acta Psychiatr Scand. 1967;43:432-443.

12. Stephens JH, Astrup C, Mangrum JC. Prognosis in schizophrenia. Prognostic scales cross validated in American and Norwegian patients. Arch Gen Psychiatry. 1967;16(6):693-698. doi: 10.1001/archpsyc.1967.01730240049008. PMID: 6027367.

13. Stephens JH. Long-term prognosis and follow up in schizophrenia. Schizophr Bull. 1978;4(1):25-47. doi: 10.1093/schbul/4.1.25. PMID: 34208.

14. Salokangas RKR. Skitsofreniaan sairastuneiden psykososiaalinen kehitys. (English Summary: The psychosocial development of schizophrenic patients.) Kansaneläkelaitoksen julkaisuja AL 7. Turku: Kansaneläkelaitos; 1977.

15. Salokangas RKR. Psychosocial prognosis in schizophrenia. Formation of the prognosis for schizophrenic patients: a multivariate analysis. Annales Universitatis Turkuensis. Ser. D. Turku: University of Turku; 1978.

16. Salokangas RK. Prognostic implications of the sex of schizophrenic patients. Br J Psychiatry. 1983;142:145-51. doi: 10.1192/bjp.142.2.145. PMID: 6839067. 
17. Salokangas RKR. Skitsofrenian hoito ja ennuste. (English Summary: Treatment and outcome in schizophrenia. Kansanterveystieteen julkaisuja M 89/85. University of Tampere Community Health Institute, University of Turku. Tampere; 1985.

18. Salokangas RK, Stengård E. Gender and short-term outcome in schizophrenia. Schizophr Res. 1990;3(5-6):333-345. doi: 10.1016/09209964(90)90019-4. PMID: 2282339.

19. Salokangas RKR, Stengård E, Räkköläinen V, Alanen YO, Kaljonen A. Treatment and Outcome of New Patients with Schizophrenia. Five-year Outcome [NSP project] (In Finnish: Uusien skitsofreniapotilaiden hoito ja ennuste [USP-projekti] V: Viiden vuoden ennuste. Reports of Psychiatria Fennica No 95. Helsinki; 1991

20. Möller HJ, von Zerssen D. Course and outcome. In Hirsch SR, Weinberger DR eds. Schizophrenia. Oxford: Blackwell Science; 1995. pp.106-127

21. Green MF, Kern RS, Braff DL, Mintz J. Neurocognitive deficits and functional outcome in schizophrenia: are we measuring the "right stuff"? Schizophr Bull. 2000;26(1):119-136. doi: 10.1093/oxfordjournals.schbul.a033430. PMID: 10755673.

22. White C, Stirling J, Hopkins R, Morris J, Montague L, Tantam D, Lewis S. Predictors of 10-year outcome of first-episode psychosis. Psychol Med. 2009;39(9):1447-56. doi: 10.1017/S003329170800514X. Epub 2009 Feb 3. PMID: 19187566.

23. Pantelis C, Yücel M, Wood SJ, McGorry PD, Velakoulis D. Early and late neurodevelopmental disturbances in schizophrenia and their functional consequences. Aust N Z J Psychiatry. 2003;37(4):399-406. doi: 10.1046/j.1440-1614.2003.01193.x. PMID: 12873323.

24. Carpenter WT, Bustillo JR, Thaker GK, van Os J, Krueger RF, Green MJ. The psychoses: cluster 3 of the proposed meta-structure for DSM-V and ICD11. Psychol Med. 2009;39(12):2025-2042. doi: 10.1017/S0033291709990286. Epub 2009 Oct 1. PMID: 19796428.

25. Rosell DR, Futterman SE, McMaster A, Siever LJ. Schizotypal personality disorder: a current review. Curr Psychiatry Rep. 2014;16(7):452. doi: 10.1007/s11920-014-0452-1. PMID: 24828284; PMCID: PMC4182925.

26. Bortolato B, Miskowiak KW, Köhler CA, Vieta E, Carvalho AF. Cognitive dysfunction in bipolar disorder and schizophrenia: a systematic review of meta-analyses. Neuropsychiatr Dis Treat. 2015;11:3111-3125. doi: 10.2147/NDT.S76700. eCollection 2015.

27. Bora E, Pantelis C. Social cognition in schizophrenia in comparison to bipolar disorder: a meta-analysis. Schizophr Res. 2016;175:72-78.

28. Green MF, Horan WP, Lee J. Nonsocial and social cognition in schizophrenia: current evidence and future directions. World Psychiatry. 2019;18(2):146-161. doi: 10.1002/wps.20624. PMID: 31059632; PMCID: PMC6502429.

29. Stirling J, White C, Lewis S, Hopkins R, Tantam D, Huddy A, Montague L. Neurocognitive function and outcome in first-episode schizophrenia: a 10year follow-up of an epidemiological cohort. Schizophr Res. 200315;65(2-3):75-86. doi: 10.1016/s0920-9964(03)00014-8. PMID: 14630300.

30. Varese F, Smeets F, Drukker M, et al. Childhood adversities increase the risk of psychosis: a meta-analysis of patient-control, prospective- and crosssectional cohort studies. Schizophr Bull. 2012;38(4):661-671. doi: 10.1093/schbul/sbs050. Epub 2012 Mar 29. PMID: 22461484; PMCID: PMC3406538.

31. Bonoldi I, Simeone E, Rocchetti M, et al. Prevalence of self-reported childhood abuse in psychosis: a meta-analysis of retrospective studies. Psychiatry Res. 2013;210(1):8-15. doi: 10.1016/j.psychres.2013.05.003. Epub 2013 Jun 20. PMID: 23790604.

32. Trauelsen AM, Bendall S, Jansen JE, et al. Childhood adversity specificity and dose-response effect in non-affective first-episode psychosis. Schizophr Res. 2015;165(1):52-9. doi: 10.1016/j.schres.2015.03.014. Epub 2015 Apr 11. PMID: 25868932.

33. Salokangas RKR, Schultze-Lutter F, Schmidt SJ, et al. Childhood physical abuse and emotional neglect are specifically associated with adult mental disorders. J Ment Health. 2020;29(4):376-384. doi: 10.1080/09638237.2018.1521940. Epub 2019 Jan 24. PMID: 30675805.

34. Yung AR, Phillips LJ, McGorry PD, et al. Prediction of psychosis. A step towards indicated prevention of schizophrenia. Br J Psychiatry Suppl. 1998;172(33):14-20. PMID: 9764121.

35. Klosterkötter J, Hellmich M, Steinmeyer EM, Schultze-Lutter F. Diagnosing schizophrenia in the initial prodromal phase. Arch Gen Psychiatry. 2001;58(2):158-164. doi: 10.1001/archpsyc.58.2.158. PMID: 11177117.

36. Miller TJ, McGlashan TH, Rosen JL, et al. Prospective diagnosis of the initial prodrome for schizophrenia based on the Structured Interview for Prodromal Syndromes: preliminary evidence of interrater reliability and predictive validity. Am J Psychiatry. 2002;159(5):863-865. doi: 10.1176/appi.ajp.159.5.863. PMID: 11986145.

37. Fusar-Poli P, Bonoldi I, Yung AR, et al. Predicting psychosis: meta-analysis of transition outcomes in individuals at high clinical risk. Arch Gen Psychiatry. 2012;69(3):220-229. doi: 10.1001/archgenpsychiatry.2011.1472. PMID: 22393215.

38. Fusar-Poli P, Cappucciati M, Borgwardt S, et al. Heterogeneity of Psychosis Risk Within Individuals at Clinical High Risk: A Meta-analytical Stratification. JAMA Psychiatry. 2016;73(2):113-20. doi: 10.1001/jamapsychiatry.2015.2324.

39. Schmidt SJ, Schultze-Lutter F, Schimmelmann BG, et al. EPA guidance on the early intervention in clinical high risk states of psychoses. Eur Psychiatry. 2015;30(3):388-404. doi: 10.1016/j.eurpsy.2015.01.013. Epub 2015 Mar 3.

40. Fusar-Poli P, Salazar de Pablo G, Correll CU, et al. Prevention of Psychosis: Advances in Detection, Prognosis, and Intervention. JAMA Psychiatry. 77(7):755-765. doi: 10.1001/jamapsychiatry.2019.4779.

41. Yung AR, Phillips LJ, Yuen HP, et al. Psychosis prediction: 12-month follow up of a high-risk ("prodromal") group. Schizophr Res. 2003;60(1):21-32. doi: 10.1016/s0920-9964(02)00167-6. PMID: 12505135

42. Cannon TD, Cadenhead K, Cornblatt B, et al. Prediction of psychosis in youth at high clinical risk: a multisite longitudinal study in North America. Arch Gen Psychiatry. 2008;65:28-37. 
43. Ruhrmann S, Schultze-Lutter F, Salokangas RK, et al. Prediction of psychosis in adolescents and young adults at high risk: results from the prospective European prediction of psychosis study. Arch Gen Psychiatry. 2010;67(3):241-51. doi: 10.1001/archgenpsychiatry.2009.206. PMID: 20194824.

44. Dragt S, Nieman DH, Schultze-Lutter F, et al.; EPOS group. Cannabis use and age at onset of symptoms in subjects at clinical high risk for psychosis. Acta Psychiatr Scand. 2012;125(1):45-53. doi: 10.1111/j.1600-0447.2011.01763.x. Epub 2011 Aug 29. PMID: 21883099.

45. Fusar-Poli P, Nelson B, Valmaggia L, Yung AR, McGuire PK. Comorbid depressive and anxiety disorders in 509 individuals with an at-risk mental state: impact on psychopathology and transition to psychosis. Schizophr Bull. 2014;40(1):120-131. doi: 10.1093/schbul/sbs136. Epub 2012 Nov 22. PMID: 23180756; PMCID: PMC3885287.

46. Salokangas RK, Dingemans P, Heinimaa M, et al; EPOS group. Prediction of psychosis in clinical high-risk patients by the Schizotypal Personality Questionnaire. Results of the EPOS project. Eur Psychiatry. 2013a;28(8):469-475. doi: 10.1016/j.eurpsy.2013.01.001. Epub 2013 Feb 8. PMID: 23394823.

47. Bolt LK, Amminger GP, Farhall J, et al. Neurocognition as a predictor of transition to psychotic disorder and functional outcomes in ultra-high risk participants: Findings from the NEURAPRO randomized clinical trial. Schizophr Res. 2019;206:67-74. doi: 10.1016/j.schres.2018.12.013. Epub 2018 Dec 14.

48. Niendam TA, Bearden CE, Johnson JK, et al. Neurocognitive performance and functional disability in the psychosis prodrome. Schizophr. Res. 2006;84:100-111. https://doi.org/10.1016/j.schres.2006.02.005

49. Addington J, Penn D, Woods SW, Addington D, Perkins DO. Social functioning in individuals at clinical high risk for psychosis. Schizophr Res. 2008;99(1-3):119-124. doi: 10.1016/j.schres.2007.10.001. Epub 2007 Nov 19. PMID: 18023329; PMCID: PMC2292799.

50. Eslami A, Jahshan C, Cadenhead KS. Disorganized Symptoms and Executive Functioning Predict Impaired Social Functioning in Subjects at Risk for Psychosis. J Neuropsychiatr. 2011;23: 457-460. https://doi.org/10.1176/appi.neuropsych.23.4.457

51. Lin A, Wood SJ, Nelson B, et al. Neurocognitive predictors of functional outcome two to 13 years after identification as ultra-high risk for psychosis. Schizophr Res. 2011;132(1):1-7. doi: 10.1016/j.schres.2011.06.014. Epub 2011 Jul 16. PMID: 21763109.

52. Carrión RE, McLaughlin D, Goldberg TE, et al. Prediction of functional outcome in individuals at clinical high risk for psychosis. JAMA Psychiatry. 2013;70(11):1133-1142. doi: 10.1001/jamapsychiatry.2013.1909. PMID: 24006090; PMCID: PMC4469070.

53. Glenthøj LB, Fagerlund B, Hjorthøj C, et al. Social cognition in patients at ultra-high risk for psychosis: What is the relation to social skills and functioning? Schizophr Res Cogn. 2016;5:21-27. https://doi.org/10.1016/j.scog.2016.06.004

54. Modinos G, Kempton MJ, Tognin S, et al; EU-GEl High Risk Study Group. Association of Adverse Outcomes With Emotion Processing and Its Neural Substrate in Individuals at Clinical High Risk for Psychosis. JAMA Psychiatry. 2020;77(2):190-200. doi: 10.1001/jamapsychiatry.2019.3501. PMID: 31722018; PMCID: PMC6865249.

55. Cotter J, Drake RJ, Bucci S, Firth J, Edge D, Yung AR. What drives poor functioning in the at-risk mental state? A systematic review. Schizophr Res. 2014;159(2-3):267-277. doi: 10.1016/j.schres.2014.09.012. Epub 2014 Sep 24.

56. Addington J, Stowkowy J, Cadenhead KS, et al. Early traumatic experiences in those at clinical high risk for psychosis. Early Interv Psychiatry. 2013;7(3):300-305. doi: 10.1111/eip.12020. Epub 2013 Jan 24. PMID: 23343384; PMCID: PMC3754436.

57. Kraan TC, Ising HK, Fokkema M, et al. The effect of childhood adversity on 4-year outcome in individuals at ultra high risk for psychosis in the Dutch Early Detection Intervention Evaluation (EDIE-NL) Trial. Psychiatry Res. 2017;247:55-62. doi: 10.1016/j.psychres.2016.11.014. Epub 2016 Nov 11. PMID: 27863320.

58. Kraan T, van Dam DS, Velthorst E, det al. Childhood trauma and clinical outcome in patients at ultra-high risk of transition to psychosis. Schizophr Res. 2015;169(1-3):193-198. doi: 10.1016/j.schres.2015.10.030. Epub 2015 Nov 14. PMID: 26585219.

59. Salokangas RKR, Patterson P, Hietala J, et al; EPOS group. Childhood adversity predicts persistence of suicidal thoughts differently in females and males at clinical high-risk patients of psychosis. Results of the EPOS project. Early Interv Psychiatry. 2019;13(4):935-942. doi: 10.1111/eip.12714. Epub 2018 Jul 23. PMID: 30033690.

60. Salokangas RK, Heinimaa M, From T, et al; EPOS group. Short-term functional outcome and premorbid adjustment in clinical high-risk patients. Results of the EPOS project. Eur Psychiatry. 2014;29(6):371-80. doi: 10.1016/j.eurpsy.2013.10.003. Epub 2013 Dec 7. PMID: 24315804.

61. Koutsouleris N, Kambeitz-llankovic L, Ruhrmann S, et al; PRONIA Consortium. Prediction Models of Functional Outcomes for Individuals in the Clinical High-Risk State for Psychosis or With Recent-Onset Depression: A Multimodal, Multisite Machine Learning Analysis. JAMA Psychiatry. 2018;75(11):1156-1172. doi: 10.1001/jamapsychiatry.2018.2165. Erratum in: JAMA Psychiatry. 2019 May 1;76(5):550. PMID: 30267047; PMCID: PMC6248111.

62. McGlashan TH, Miller TJ, Woods SW. Structured interview for prodromal syndromes. Version 3.0 Connecticut, New Haven: Yale School of Medicine, PRIME Research Clinic; 2001

63. McGlashan T, Walsh B, Woods S. The psychosis-risk syndrome: handbook for diagnosis and follow-up. Oxford: Oxford University Press; 2010.

64. Cannon-Spoor HE, Potkin SG, Wyatt RJ. Measurement of premorbid adjustment in chronic schizophrenia. Schizophr Bull. 1982;8:470-484.

65. First MB, Spitzer RL, Gibbon M, Williams JBW. Structured Clinical Interview for DSM-IV-TR Axis I Disorders, Research Version, Patient Edition. (SCIDI/P). New York: Biometrics Research, New York State Psychiatric Institute; 2002. 
66. Patterson P, Skeate A, Schultze-Lutter F, Graf von Reventlow H, Wieneke A, Ruhrmann S, Salokangas R. The Trauma and Distress Scale. Birmingham, UK: University of Birmingham; 2002.

67. Salokangas RKR, Schultze-Lutter F, Patterson P, et al. Psychometric properties of the Trauma and Distress Scale, TADS, in an adult community sample in Finland. Eur J Psychotraumatol. 2016;7:30062

68. Blumenthal JA, Burg MM, Barefoot J, Williams RB, Haney T, Zimet G. Social support, type A behavior, and coronary artery disease. Psychosom Med. 1987;49(4):331-340. doi: 10.1097/00006842-198707000-00002. PMID: 3615762.

69. Wechsler D. Wechsler Adult Intelligence Scale - III, Cleveland, Ohio: The Psychological Corporation. Finnish translation. Helsinki: Psykologien Kustannus Oy; 2005.

70. Blair JR, Spreen O. Predicting premorbid IQ: A revision of the National Adult Reading Test. Clinical Neuropsychologist. 1989; 3:129-136.

71. Spreen O, Strauss E. A compendium of neuropsychological tests. Oxford University Press: New York, Oxford, 1998.

72. Reitan RM, TMT, Trail Making Test A \& B, 1992.

73. Wechsler D. Wechsler Memory Scale (3rd ed.) The Psychological Corporation, Harcourt Brace Jovanovich, New York. Finnish translation. Helsinki: Psykologien Kustannus Oy; 2008.

74. Brandt J, Benedict RHB. Hopkins verbal learning test - Revised. Administration manual. Lutz FL: Psychological Assessment Resources; 2001.

75. Benedict RHB. Brief visuospatial memory test - revised: Professional manual. Lutz, FL: Psychological Assessment Resources Inc; 1997.

76. White T, Stern RA. Neuropsychological Assessment Battery (NAB): Demographically Corrected Norms Manual. Lutz, FL: Psychological Assessment Resources Inc; 2003.

77. Exner JE. The Rorschach: A Comprehensive System. Vol. 1, 4th Edition, Basic Foundations Basic Foundations and Principles of Interpretation. New York: Wiley; 2003.

78. Mihura JL, Meyer GJ, Dumitrascu N, Bombel G. The validity of individual Rorschach variables: systematic reviews and meta-analyses of the comprehensive system. Psychol Bull. 2013;139(3):548-605. doi: 10.1037/a0029406. Epub 2012 Aug 27. PMID: 22925137.

79. Heaton RK, Chelune GJ, Talley JL, Kay GG, Curtiss G. Wisconsin Card Sorting Test Manual: Revised and Expanded. Odessa, FL: Psychological Assessment Resources; 1993.

80. Mayer JD, Salovey P, Caruso D. MSCEIT technical manual. Toronto: Multi-Health Systems; 2002.

81. Cassidy CM, Norman R, Manchanda R, Schmitz N, Malla A. Testing definitions of symptom remission in first-episode psychosis for prediction of functional outcome at 2 years. Schizophr Bull. 2010;36(5):1001-1008. doi: 10.1093/schbul/sbp007. Epub 2009 Mar 25. PMID: 19321629; PMCID: PMC2930352.

82. Lally J, Ajnakina O, Stubbs B, Cullinane M, Murphy KC, Gaughran F, Murray RM. Remission and recovery from first-episode psychosis in adults: systematic review and meta-analysis of long-term outcome studies. Br J Psychiatry. 2017;211(6):350-358. doi: 10.1192/bjp.bp.117.201475. Epub 2017 Oct 5. PMID: 28982659.

83. Zigler E, Phillips L. Social competence and outcome in psychiatric disorders. J Abnorm Soc Psychol. 1961;63:264-271.

84. Zigler E, Phillips L. Social competence and the process-reactive distinction in psychopathology. J Abnorm Soc Psychol. 1962;65:215-22. doi: 10.1037/h0040765. PMID: 14003638.

85. Salokangas RK, Honkonen T, Stengård E, Koivisto AM. To be or not to be married-that is the question of quality of life in men with schizophrenia. Soc Psychiatry Psychiatr Epidemiol. 2001;36(8):381-390. doi: 10.1007/s001270170028. PMID: 11766968.

86. Salokangas RK, Nieman DH, Heinimaa M, et al.; EPOS group. Psychosocial outcome in patients at clinical high risk of psychosis: a prospective follow-up. Soc Psychiatry Psychiatr Epidemiol. 2013b;48(2):303-311. doi: 10.1007/s00127-012-0545-2. Epub 2012 Jul 15. PMID: 22797132.

87. Ventura J, Hellemann GS, Thames AD, Koellner V, Nuechterlein KH. Symptoms as mediators of the relationship between neurocognition and functional outcome in schizophrenia: a meta-analysis. Schizophr Res. 2009 Sep;113(2-3):189-99. doi: 10.1016/j.schres.2009.03.035. Epub 2009 Jul 22. PMID: 19628375; PMCID: PMC2825750.

88. Webb JR, Addington J, Perkins DO, et al. Specificity of Incident Diagnostic Outcomes in Patients at Clinical High Risk for Psychosis. Schizophr Bull. 2015;41(5):1066-1075. doi: 10.1093/schbul/sbv091. Erratum in: Schizophr Bull. 2018;44(4):933-935. PMID: 26272875; PMCID: PMC4535651.

89. Fusar-Poli P, Rutigliano G, Stahl D, et al. Long-term validity of the At Risk Mental State (ARMS) for predicting psychotic and non-psychotic mental disorders. Eur Psychiatry. 2017;42:49-54. doi: 10.1016/j.eurpsy.2016.11.010. Epub 2016 Dec 6. PMID: 28212505.

90. Woods SW, Powers AR 3rd, Taylor JH, et al. Lack of Diagnostic Pluripotentiality in Patients at Clinical High Risk for Psychosis: Specificity of Comorbidity Persistence and Search for Pluripotential Subgroups. Schizophr Bull. 2018;"44(2):254-263. doi: 10.1093/schbul/sbx138. PMID: 29036402; PMCID: PMC5814797.

91. Kraan TC, Velthorst E, Themmen M, et al. EU-GEl High Risk Study. Child Maltreatment and Clinical Outcome in Individuals at Ultra-High Risk for Psychosis in the EU-GEl High Risk Study. Schizophr Bull. 2018;44(3):584-592. doi: 10.1093/schbul/sbw162. PMID: 28666366; PMCID: PMC5890491.

92. Salokangas RK, Ruhrmann S, von Reventlow HG, et al; EPOS group. Axis I diagnoses and transition to psychosis in clinical high-risk patients EPOS project: prospective follow-up of 245 clinical high-risk outpatients in four countries. Schizophr Res. 2012;138(2-3):192-197. doi:

10.1016/j.schres.2012.03.008. Epub 2012 Mar 31. PMID: 22464922.

Page 10/17 
93. Falkenberg I, Valmaggia L, Byrnes M, et al. Why are help-seeking subjects at ultra-high risk for psychosis help-seeking? Psychiatry Res. 2015;228(3):808-815. doi: 10.1016/j.psychres.2015.05.018. Epub 2015 May 30. PMID: 26071897.

94. Rutigliano G, Valmaggia L, Landi P, et al. Persistence or recurrence of non-psychotic comorbid mental disorders associated with 6-year poor functional outcomes in patients at ultra high risk for psychosis. J Affect Disord. 2016;203:101-110. doi: 10.1016/j.jad.2016.05.053. Epub 2016 May 31. PMID: 27285723.

95. Kahn RS, Sommer IE, Murray RM, et al. Schizophrenia. Nat Rev Dis Primers. 2015;1:15067. doi: 10.1038/nrdp.2015.67. PMID: 27189524.

96. Rosenheck R, Mueser KT, Sint K, et al. Supported employment and education in comprehensive, integrated care for first episode psychosis: Effects on work, school, and disability income. Schizophr Res. 2017;182:120-128. doi: 10.1016/j.schres.2016.09.024. Epub 2016 Sep 23. PMID: 27667369.

97. Modini M, Tan L, Brinchmann B, et al. Supported employment for people with severe mental illness: systematic review and meta-analysis of the international evidence. Br J Psychiatry. 2016;209(1):14-22. doi: 10.1192/bjp.bp.115.165092. Epub 2016 Apr 21. PMID: 27103678.

98. Bell MD, Bryson GJ, Greig TC, Fiszdon JM, Wexler BE. Neurocognitive enhancement therapy with work therapy: Productivity outcomes at 6- and 12month follow-ups. J Rehabil Res Dev. 2005;42(6):829-38. doi: 10.1682/jrrd.2005.03.0061. PMID: 16680620.

99. Bell MD, Choi KH, Dyer C, Wexler BE. Benefits of cognitive remediation and supported employment for schizophrenia patients with poor community functioning. Psychiatr Serv. 2014;65(4):469-475. doi: 10.1176/appi.ps.201200505. PMID: 24382594.

100. Chan JY, Hirai HW, Tsoi KK. Can computer-assisted cognitive remediation improve employment and productivity outcomes of patients with severe mental illness? A meta-analysis of prospective controlled trials. J Psychiatr Res. 2015;68:293-300. doi: 10.1016/j.jpsychires.2015.05.010. Epub 2015 May 21. PMID: 26028551.

\section{Tables}


Table 1.

Sociodemographic background and baseline characteristics of the TEPS sample.

\begin{tabular}{|c|c|c|c|c|c|}
\hline & FEP† & CHR-P $\ddagger$ & CHR-N§ & All & $\mathrm{p}$ \\
\hline Gender (\%) & $n=130$ & $n=60$ & $n=47$ & $n=237$ & 0.831 \\
\hline Male & 56.2 & 51.7 & 53.2 & 54.4 & \\
\hline Female & 43.8 & 48.3 & 46.8 & 45.6 & \\
\hline Age (years) & $n=130$ & $n=60$ & $n=47$ & $\mathrm{n}=237$ & 0.289 \\
\hline $18-23$ & 37.7 & 53.3 & 46.8 & 43.5 & \\
\hline $24-29$ & 33.1 & 23.3 & 23.4 & 28.7 & \\
\hline $30-49$ & 29.2 & 23.3 & 29.8 & 27.8 & \\
\hline mean (SD) & $26.5(5.9)$ & $25.0(6.2)$ & $27.1(7.9)$ & $26.3(6.4)$ & 0.195 \\
\hline Marital status (\%) & $n=130$ & $n=60$ & $n=47$ & $n=237$ & 0.536 \\
\hline Single & 72.3 & 71.7 & 63.8 & 70.5 & \\
\hline Ever married/divorced & 27.7 & 28.3 & 36.2 & 29.5 & \\
\hline Living with & $n=130$ & $n=60$ & $n=47$ & $n=237$ & 0.960 \\
\hline Alone & 47.7 & 45.0 & 46.8 & 46.8 & \\
\hline Own family/children & 30.0 & 30.0 & 31.9 & 30.4 & \\
\hline Parents/sisters & 16.2 & 20.0 & 12.8 & 16.5 & \\
\hline Other persons & 6.2 & 5.0 & 8.5 & 6.3 & \\
\hline Basic education (\%) & $n=130$ & $n=60$ & $n=47$ & $n=237$ & 0.490 \\
\hline Comprehensive school or less & 40.0 & 41.7 & 44.7 & 41.4 & \\
\hline High school & 13.8 & 6.7 & 6.4 & 10.5 & \\
\hline College & 46.2 & 51.7 & 48.9 & 48.1 & \\
\hline Professional school & $n=130$ & $\mathrm{n}=60$ & $n=47$ & $n=237$ & 0.797 \\
\hline None & 43.8 & 48.3 & 42.6 & 44.7 & \\
\hline Vocational school & 41.5 & 43.3 & 42.6 & 42.2 & \\
\hline University & 14.6 & 8.3 & 14.9 & 13.1 & \\
\hline Years of education; mean (SD) & $13.8(3.1)$ & $13.2(2.9)$ & $13.9(3.4)$ & $13.7(3.1)$ & 0.382 \\
\hline Work situation (\%) & $n=130$ & $n=60$ & $\mathrm{n}=47$ & $n=237$ & 0.574 \\
\hline Working & 60.0 & 58.3 & 61.7 & 59.9 & \\
\hline Unemployed & 19.2 & 30.0 & 21.3 & 22.4 & \\
\hline Sick leave & 10.8 & 6.7 & 6.4 & 8.9 & \\
\hline Temporary retirement & 10.0 & 5.0 & 10.6 & 8.9 & \\
\hline Confident support (score) & $n=104$ & $\mathrm{n}=48$ & $n=42$ & $n=194$ & \\
\hline mean, SD & $31.4(11.5)$ & 27.4(10.7) & $29.7(7.7)$ & $30.0(10.7)$ & 0.102 \\
\hline SCID Diagnosis (\%) & $n=130$ & $n=60$ & $n=47$ & $n=237$ & $<0.001$ \\
\hline No & 0.0 & 8.3 & 6.4 & 3.4 & \\
\hline Bipolar & 16.9 & 3.3 & 8.5 & 11.8 & \\
\hline Depression & 16.9 & 56.7 & 63.8 & 36.3 & \\
\hline Non-affective Psychosis & 66.2 & 5.0 & 0.0 & 37.6 & \\
\hline Anxiety & 0.0 & 26.7 & 21.3 & 11.0 & \\
\hline SIPS symptom score mean (SD) & $n=125$ & $n=60$ & $\mathrm{n}=47$ & $n=232$ & \\
\hline Positive (0-30) & $16.5(5.3)$ & $10.6(5.9)$ & $5.9(4.2)$ & $12.8(6.4)$ & $<0.001$ \\
\hline
\end{tabular}




\begin{tabular}{|c|c|c|c|c|c|}
\hline Negative (0-30) & $11.0(7.3)$ & $11.4(6.6)$ & $10.2(6.1)$ & $10.9(6.8)$ & 0.645 \\
\hline Disorganised (0-24) & $5.4(4.1)$ & $4.8(3.5)$ & $3.4(2.3)$ & $4.9(3.7)$ & 0.006 \\
\hline General (0-24) & $6.8(4.6)$ & 7.7(3.3) & $6.3(3.8)$ & $6.9(4.1)$ & 0.166 \\
\hline TADS score mean (SD) & $n=107$ & $\mathrm{n}=48$ & $\mathrm{n}=40$ & $n=195$ & \\
\hline EmoAb (1-5) & $4.7(4.3)$ & $5.3(4.4)$ & $5.4(4.8)$ & $5.0(4.4)$ & 0.586 \\
\hline PhyAb (1-5) & $1.7(2.1)$ & $1.8(2.6)$ & $2.3(3.9)$ & $1.9(2.7)$ & 0.508 \\
\hline SexAb (1-5) & $1.2(3.1)$ & $0.6(1.6)$ & $1.2(3.9)$ & 1.1(3.0) & 0.520 \\
\hline EmoNeg (1-5) & $6.8(5.0)$ & $7.5(5.1)$ & $8.3(4.1)$ & 7.3(4.9) & 0.241 \\
\hline PhyNeg (1-5) & $3.4(2.8)$ & 3.3(3.1) & $4.4(3.5)$ & $3.5(3.1)$ & 0.156 \\
\hline PAS score mean (SD) & $n=124$ & $n=57$ & $n=47$ & $n=228$ & \\
\hline-11 years $(0-24)$ & $6.2(3.6)$ & $6.8(3.3)$ & $6.6(3.6)$ & $6.5(3.5)$ & 0.495 \\
\hline $12-15$ years $(0-30)$ & $10.1(5.2)$ & $10.8(4.9)$ & $10.0(4.1)$ & $10.3(4.9)$ & 0.669 \\
\hline $16-18$ years $(0-30)$ & $10.9(5.6)$ & $10.9(5.9)$ & $10.4(3.8)$ & $10.8(5.3)$ & 0.839 \\
\hline \multicolumn{6}{|c|}{ †First-episode psychosis; ¥Confirmed clinical high-risk to psychosis; } \\
\hline \multicolumn{6}{|c|}{ §Non-confirmed clinical high risk to psychosis } \\
\hline \multicolumn{6}{|c|}{ EmoAb = Emotional abuse; PhyAb = Physical abuse; SexAb = Sexual abuse; } \\
\hline \multicolumn{6}{|c|}{ EmoNeg = Emotional neglect; PhyAb = Physical Abuse; $P A S=$ Premorbid adjustment } \\
\hline
\end{tabular}


Table 2.

Neuropsychological tests by diagnostic groups.

\begin{tabular}{|c|c|c|c|c|c|c|c|c|c|c|c|c|}
\hline & \multicolumn{2}{|c|}{$\begin{array}{l}\text { FEP } \\
(n=119)\end{array}$} & \multicolumn{2}{|c|}{$\begin{array}{l}\text { CHR-P } \ddagger \\
(n=54)\end{array}$} & \multicolumn{2}{|c|}{$\begin{array}{l}\text { CHR-N§ } \\
(n=46)\end{array}$} & \multicolumn{3}{|c|}{$\begin{array}{l}\text { All } \\
(n=219)\end{array}$} & \multirow{2}{*}{$\begin{array}{l}\text { FEP/ } \\
\text { CHR- } \\
P \\
\text { p2 }\end{array}$} & \multirow{2}{*}{$\begin{array}{l}\text { FEP/ } \\
\text { CHR-N } \\
\text { p3 }\end{array}$} & \multirow{2}{*}{$\begin{array}{l}\text { CHR- } \\
\text { P/ } \\
\text { CHR- } \\
\text { N } \\
\text { p4 }\end{array}$} \\
\hline & Mean & SD & Mean & SD & Mean & SD & Mean & SD & $\mathrm{p} 1$ & & & \\
\hline \multicolumn{13}{|l|}{ Verbal skills } \\
\hline WAIS III Vocabulary & 42.61 & 10.84 & 42.80 & 10.57 & 43.07 & 10.85 & 50.14 & 7.54 & 0.970 & 0.914 & 0.806 & 0.901 \\
\hline MCCB Category Fluency & 22.23 & 5.71 & 22.98 & 5.24 & 24.52 & 7.39 & 24.36 & 6.12 & 0.090 & 0.444 & 0.029 & 0.202 \\
\hline MCCB S-words & 15.11 & 5.56 & 15.54 & 5.48 & 16.83 & 4.45 & 16.51 & 5.40 & 0.180 & 0.625 & 0.065 & 0.229 \\
\hline \multicolumn{13}{|l|}{ Attention/vigilance } \\
\hline TMT-A & 32.94 & 10.18 & 28.17 & 8.33 & 31.52 & 10.93 & 29.70 & 9.83 & 0.015 & 0.004 & 0.411 & 0.093 \\
\hline TMT-B & 92.18 & 66.00 & 86.24 & 82.34 & 66.50 & 38.08 & 75.81 & 58.28 & 0.082 & 0.583 & 0.026 & 0.137 \\
\hline \multicolumn{13}{|l|}{ Speed of processing } \\
\hline WAIS III Digit Symbol & 66.37 & 15.78 & 73.44 & 16.85 & 74.59 & 15.54 & 75.24 & 16.97 & 0.002 & 0.008 & 0.003 & 0.722 \\
\hline \multicolumn{13}{|l|}{ Working memory } \\
\hline WAIS III Letter-Number Span & 9.97 & 2.22 & 10.59 & 2.02 & 11.17 & 2.34 & 10.94 & 2.38 & 0.006 & 0.088 & 0.002 & 0.189 \\
\hline WMS-R Spatial Span & 16.87 & 3.01 & 17.57 & 2.95 & 17.22 & 2.15 & 17.63 & 2.88 & 0.313 & 0.126 & 0.477 & 0.523 \\
\hline \multicolumn{13}{|l|}{ Verbal learning } \\
\hline HVLT immediate & 25.94 & 4.29 & 27.31 & 4.60 & 28.89 & 3.95 & 27.79 & 4.43 & $<0.001$ & 0.053 & $<0.001$ & 0.069 \\
\hline HVLT delayed & 9.18 & 2.12 & 10.19 & 1.90 & 10.35 & 1.72 & 10.04 & 1.95 & $<0.001$ & 0.002 & 0.001 & 0.684 \\
\hline \multicolumn{13}{|l|}{ Visual learning } \\
\hline MCCB BVMT-R & 24.37 & 6.98 & 26.96 & 6.43 & 26.65 & 6.51 & 26.87 & 6.59 & 0.029 & 0.020 & 0.053 & 0.819 \\
\hline \multicolumn{13}{|l|}{ Reasoning and problem solving } \\
\hline MCCB NAB Mazes & 20.43 & 4.89 & 22.07 & 3.59 & 22.24 & 4.15 & 21.78 & 4.18 & 0.018 & 0.025 & 0.020 & 0.854 \\
\hline \multicolumn{13}{|l|}{ WCST } \\
\hline Total number of errors & 30.20 & 24.54 & 28.24 & 19.23 & 22.35 & 18.18 & 28.07 & 22.22 & 0.125 & 0.589 & 0.042 & 0.185 \\
\hline Perseverative responses & 18.73 & 19.06 & 16.63 & 12.98 & 12.91 & 11.21 & 16.99 & 16.39 & 0.122 & 0.433 & 0.041 & 0.257 \\
\hline Perseverative errors & 16.36 & 15.00 & 15.11 & 10.91 & 11.87 & 9.47 & 15.11 & 13.12 & 0.143 & 0.560 & 0.049 & 0.218 \\
\hline Percent conceptual level responses & 64.51 & 21.74 & 66.07 & 16.94 & 71.46 & 17.17 & 66.36 & 19.84 & 0.130 & 0.630 & 0.044 & 0.176 \\
\hline Number of categories completed & 4.96 & 1.68 & 5.11 & 1.42 & 5.39 & 1.31 & 5.09 & 1.55 & 0.272 & 0.547 & 0.108 & 0.368 \\
\hline \multicolumn{13}{|l|}{ Ro-Exner (RCS) } \\
\hline Perceptual thinking index (PTI) & 1.25 & 1.34 & 1.37 & 1.19 & 0.70 & 1.07 & 1.16 & 1.27 & 0.016 & 0.566 & 0.011 & 0.008 \\
\hline Distorted perception (X-\%) & 0.28 & 0.11 & 0.28 & 0.09 & 0.21 & 0.08 & 0.26 & 0.10 & 0.001 & 0.824 & 0.001 & 0.002 \\
\hline Incoherent thinking (WSum6) & 9.90 & 8.70 & 9.69 & 7.56 & 7.02 & 6.50 & 9.24 & 8.06 & 0.108 & 0.871 & 0.040 & 0.099 \\
\hline Appropriate answers (XA\%) & 0.70 & 0.12 & 0.70 & 0.09 & 0.76 & 0.09 & 0.71 & 0.11 & 0.002 & 0.923 & 0.001 & 0.003 \\
\hline $\begin{array}{l}\text { Extended appropriate answers } \\
\text { (WDA\%) }\end{array}$ & 0.73 & 0.12 & 0.73 & 0.09 & 0.79 & 0.08 & 0.75 & 0.11 & 0.003 & 0.902 & 0.001 & 0.005 \\
\hline
\end{tabular}


Table 3.

Functioning at T0, T1 and T2 (A) and paired differences for GAFT0, GAFT1 and GAFT2 (B) by diagnostic groups

\begin{tabular}{|c|c|c|c|c|c|c|c|c|c|c|c|c|c|c|c|}
\hline \multirow[t]{2}{*}{ A } & \multicolumn{3}{|l|}{ FEP† } & \multicolumn{3}{|c|}{ CHR-P $\ddagger$} & \multicolumn{3}{|c|}{ CHR-N§ } & \multicolumn{3}{|l|}{ ALL } & \multicolumn{3}{|l|}{ p1 } \\
\hline & TO & T1 & $\mathrm{T} 2$ & T0 & $\mathrm{T} 1$ & $\mathrm{~T} 2$ & T0 & $\mathrm{T} 1$ & $\mathrm{~T} 2$ & TO & $\mathrm{T} 1$ & $\mathrm{~T} 2$ & TO & $\mathrm{T} 1$ & $\mathrm{~T} 2$ \\
\hline & $n=130$ & $n=130$ & $n=129$ & $n=60$ & $n=59$ & $n=59$ & $n=47$ & $n=47$ & $n=47$ & $n=237$ & $n=236$ & $\mathrm{n}=235$ & & & \\
\hline \multicolumn{16}{|l|}{ GAF (\%) } \\
\hline $\begin{array}{c}\text { Good } \\
(61-100)\end{array}$ & 15.4 & 37.7 & 43.4 & 18.3 & 32.2 & 44.1 & 25.5 & 42.6 & 48.9 & 18.1 & 37.3 & 44.7 & $<0.001$ & 0.053 & 0.053 \\
\hline $\begin{array}{l}\text { Moderate } \\
(41-60)\end{array}$ & 46.2 & 33.8 & 29.5 & 66.7 & 54.2 & 45.8 & 70.2 & 38.3 & 34.0 & 56.1 & 39.8 & 34.5 & & & \\
\hline $\begin{array}{l}\text { Poor (0- } \\
40)\end{array}$ & 38.5 & 28.5 & 27.1 & 15.0 & 13.6 & 10.2 & 4.3 & 19.1 & 17.0 & 25.7 & 22.9 & 20.9 & & & \\
\hline Mean & 48.0 & 57.1 & 59.3 & 53.7 & 56.6 & 62.2 & 58.2 & 59.4 & 61.6 & 51.4 & 57.4 & 60.5 & $<0.001$ & 0.679 & 0.548 \\
\hline SD & 14.4 & 18.7 & 19.7 & 10.8 & 15.1 & 17.2 & 9.1 & 16.2 & 17.4 & 13.2 & 17.3 & 18.6 & & & \\
\hline
\end{tabular}

\begin{tabular}{|lllll|}
\hline B & Mean & SD & $t$ & $\mathrm{p}$ \\
\hline FEP $(\mathrm{df}=128-129)$ & & & & \\
\hline GAFT0 - GAFT1 & -9.18 & 17.75 & -5.90 & $<0.001$ \\
\hline GAFT0 - GAFT2 & -11.48 & 18.95 & -6.88 & $<0.001$ \\
\hline GAFT1 - GAFT2 & -2.31 & 14.00 & -1.87 & 0.063 \\
\hline CHR-P (df=58) & & & & \\
\hline GAFT0 - GAFT1 & -2.31 & 13.61 & -1.30 & 0.198 \\
\hline GAFT0 - GAFT2 & -7.88 & 17.84 & -3.39 & 0.001 \\
\hline GAFT1 - GAFT2 & -5.58 & 15.07 & -2.84 & 0.006 \\
\hline CHR-N (df=46) & & & & \\
\hline GAFT0 - GAFT1 & -1.23 & 16.86 & -0.50 & 0.618 \\
\hline GAFT0 - GAFT2 & -3.47 & 16.43 & -1.45 & 0.155 \\
\hline GAFT1 - GAFT2 & -2.23 & 8.31 & -1.84 & 0.072 \\
\hline ALL (df=234-235) & & & & \\
\hline GAFT0 - GAFT1 & -5.88 & 16.96 & -5.32 & $<0.001$ \\
\hline GAFT0 - GAFT2 & -8.97 & 18.39 & -7.48 & $<0.001$ \\
\hline GAFT1 - GAFT2 & -3.11 & 13.38 & -3.57 & $<0.001$ \\
\hline
\end{tabular}


Table 4.

Repeated measures ANOVA of follow-up functioning for all patients

\begin{tabular}{|c|c|c|c|c|c|}
\hline Between subjects effect & df & $\mathrm{F}$ & $\mathrm{p}$ & Par. $\eta^{2}$ & \\
\hline Basic education & 2 & 6.219 & 0.002 & 0.057 & \\
\hline Work situation & 3 & 9.295 & $<0.001$ & 0.120 & \\
\hline SIPS disorganised symptoms & 1 & 24.621 & $<0.001$ & 0.108 & \\
\hline Appropriate answers (XA\%) & 1 & 4.141 & 0.043 & 0.020 & \\
\hline Late adolescence PAS & 1 & 18.292 & $<0.001$ & 0.082 & \\
\hline Parameter estimations & B & $\mathrm{t}$ & $\mathrm{p}$ & $\mathrm{Cl} 95 \%$ & \\
\hline \multicolumn{6}{|l|}{ GAFT0 } \\
\hline Comprehensive school or less & 0.810 & 0.487 & 0.627 & -2.471 & 4.090 \\
\hline High school & -2.735 & -1.089 & 0.277 & -7.686 & 2.217 \\
\hline College & - & & & & \\
\hline Working & 9.598 & 3.531 & 0.001 & 4.239 & 14.958 \\
\hline Unemployed & 8.315 & 2.781 & 0.006 & 2.420 & 14.209 \\
\hline Sick leave & 3.419 & 0.963 & 0.337 & -3.579 & 10.417 \\
\hline Temporary retirement & - & & & & \\
\hline SIPS disorganised symptoms & -1.304 & -5.807 & $<0.001$ & -1.746 & -0.861 \\
\hline Appropriate answers (XA\%) & 20.320 & 2.846 & 0.005 & 6.242 & 34.397 \\
\hline Late adolescence PAS & -0.234 & -1.480 & 0.140 & -0.546 & 0.078 \\
\hline \multicolumn{6}{|l|}{ GAFT1 } \\
\hline Comprehensive school or less & -4.445 & -2.051 & 0.042 & -8.719 & -0.172 \\
\hline High school & -9.311 & -2.846 & 0.005 & -15.760 & -2.861 \\
\hline College & - & & & & \\
\hline Working & 11.886 & 3.357 & 0.001 & 4.905 & 18.868 \\
\hline Unemployed & 5.130 & 1.318 & 0.189 & -2.547 & 12.808 \\
\hline Sick leave & 6.226 & 1.347 & 0.180 & -2.890 & 15.341 \\
\hline Temporary retirement & - & & & & \\
\hline SIPS disorganised symptoms & -1.013 & -3.464 & 0.001 & -1.590 & -0.436 \\
\hline Appropriate answers (XA\%) & 14.654 & 1.576 & 0.117 & -3.683 & 32.990 \\
\hline Late adolescence PAS & -0.749 & -3.639 & $<0.001$ & -1.155 & -0.343 \\
\hline \multicolumn{6}{|l|}{ GAFT2 } \\
\hline Comprehensive school or less & -5.989 & -2.524 & 0.012 & -10.668 & -1.310 \\
\hline High school & -11.616 & -3.243 & 0.001 & -18.677 & -4.554 \\
\hline College & - & & & & \\
\hline Working & 14.368 & 3.706 & $<0.001$ & 6.725 & 22.012 \\
\hline Unemployed & 5.419 & 1.271 & 0.205 & -2.986 & 13.825 \\
\hline Sick leave & 8.805 & 1.739 & 0.083 & -1.175 & 18.785 \\
\hline Temporary retirement & - & & & & \\
\hline SIPS disorganised symptoms & -0.809 & -2.526 & 0.012 & -1.440 & -0.178 \\
\hline Appropriate answers (XA\%) & 5.791 & 0.569 & 0.570 & -14.284 & 25.867 \\
\hline Late adolescence PAS & -0.914 & -4.053 & $<0.001$ & -1.358 & -0.469 \\
\hline
\end{tabular}

Page $16 / 17$ 


\section{Supplementary Files}

This is a list of supplementary files associated with this preprint. Click to download.

- SupplementaryTable1.xlsx

- SupplementaryTable2.xlsx

- SupplementaryTable3.xlsx

- SupplementaryTables4a4b4c.docx

- Supplementarymaterial.docx 